\title{
Three Hundred Years of Crisis in Economic Dictionaries and Encyclopaedias
}

\begin{abstract}
This article discusses the book Crises and Cycles in Economic Dictionaries and Encyclopaedias from a lexicographical point of view. Although the book is mainly written to people interested in the history of economics and the evolution of the two concepts mentioned in the title, its fresh approach places it directly, although incidentally, in the on-going discussion on the academic character of lexicography. After briefly presenting the main content of the book, the article discusses the relation between economics and lexicography from various angles. Finally, it points to some elements where the book may contribute to the enrichment of lexicographical theory.
\end{abstract}

\section{Introduction}

After spending decades in the world of lexicography and reading tens of thousands of pages about dictionaries and other lexicographical works, it is seldom that one gets really surprised when reading a new book on the topic and it is even rarer that the surprise is most enjoyable. This, however, was what happened when receiving and later reading Crises and Cycles in Economic Dictionaries and Encyclopaedias edited by the Swiss researcher in the history of economic thought Daniele Besomi (2011). Although the main intention of this book is to analyse how the concepts of crisis and business cycle have been treated and defined in lexicographical works of economics during the past centuries, its fresh approach places it directly, although incidentally, in the on-going discussion on the character of lexicography providing new and interesting arguments in favour of the independent academic status of this discipline as well as its great interdisciplinary vocation.

A book dealing with crises and cycles in dictionaries and encyclopaedias can be reviewed along two main lines: one from the point of view of the history of economic thought, and the other from the point of view of lexicography, each approach requiring a subject-field expert from the respective branch of knowledge and leading to a very different type of review. Although the most all-round review of a book with the characteristics mentioned would undoubtedly be the one based upon a combination of both types of knowledge, in this article the approach will exclusively be lexicographical with a view to generating new knowledge to be used within the field of specialised as well as general lexicography.

\section{The content}

Research into the history of economics is a well-established academic discipline embracing a considerable number of scholars, chairs, specialised journals, and international conferences. The specific project behind the book in question is one of the outcomes of an international research project on business cycle and crisis theories. Apart from the editor, the contributors are François Allison (Switzerland), Pier Francesco Asso (Italy), Jesús Astigarraga (Spain), Vincent Barnett (UK), Pascal Bridel (Switzerland), Giorgio Colacchio (Italy), Cécile Dangel-Hagnauer (France), Luca Fiorito (Italy), Ludovic Frobert (France), Vitantonio Gioia (Italy), Harald Hagemann (Germany),

\footnotetext{
* Sven Tarp

Department of Business Communication

School of Business and Social Sciences

Aarhus University

Jens Chr. Skous Vej 4

DK-8000 Aarhus $C$

st@asb.dk
} 
Francisco Louça (Portugal), Jan-Peter Olters (Montenegro), Marc Pilkington (France), Peter Rodenburg (Netherland), and Juan Zabalza (Spain), all of them specialists in various aspects of the history of economics.

Crises and Cycles in Economic Dictionaries and Encyclopaedias is composed of three main parts including 29 systematically organised chapters written individually or jointly by the 17 scholars listed above; it comprises a total of 676 pages, of which the editor himself has contributed with more than half.

The first part of the book consists of four chapters, all of them written by Daniel Besomi. Chapter 1 discusses dictionaries as a "literary genre" and their relation to the history of economic thought. Chapter 2 contains a brief and concentrated history of economic dictionaries starting with Noel Chomel's Dictionnaire oeconomique from 1709, as well as a preliminary attempt to classify these works. Chapter 3 traces the semantics and chronology of some of the terms which have been used to name the phenomena in question during the centuries, i.e. terms like glut, distress, embarrassment, stagnation, panic, bubble, depression, crisis, cycle, fluctuations, and recession. Finally, Chapter 4 discusses the problems related to the categorisation of business cycle theories providing an overview of how the history of the theories of crises and cycles is reconstructed by means of dictionaries and encyclopaedias. This part of the book is by far the most interesting from a lexicographical point of view.

The second part constitutes the bulk of the book and comprises 19 chapters distributed on 276 pages. These chapters vary considerably in style but are united by the fact that they are all devoted to one or a few significant lexicographical articles on crises or cycles, all of them taken from a number of "classical" dictionaries or encyclopaedias, mostly published before the Second World War. Through the analysis of these articles and their interaction with the contemporary economic theories, the evolution of the thought on crises and cycles is documented from époque to époque, from country to country, from school to school, from author to author. Even for a layman or semiexpert in economics this part of the book represents a unique and fascinating journey through the history of a phenomenon so relevant to all of us today.

The third part comprises six chapters, five of which are dedicated to the treatment of a specific theme in recent dictionaries and encyclopaedias, i.e. long waves, political business cycles, real and equilibrium business cycles, non-linear business cycles, and crisis. The last chapter is a user-friendly 70-pages bibliography of the more than 650 economic dictionaries and encyclopaedias published since 1709 and making up the bulk of the research material on which the book and its individual contributions are based. Many of these works, especially the older ones, are today made freely available for research on archive.org, books.google.com, and other Internet sites.

As a whole, Crises and Cycles in Economic Dictionaries and Encyclopaedias appears as a well-written, well-structured, and highly informative piece of research, in which the expounded ideas and conclusions are documented by means of dictionaries, encyclopaedias, and other relevant sources. Its seems to provide new and relevant knowledge on the evolution of economic thought, but whether this is really the case or not should necessarily by evaluated and judged by an expert in the history of economics.

\section{Lexicography and economics}

As already mentioned, the main intention of the book is to analyse how the concepts of crisis and business cycle have been treated in dictionaries and encyclopaedias with a view to tracing the evolution of the corresponding economic thought during the past centuries. The Argentinian economist Jorge Beinstein (2005) writes the following about this complex question:

\footnotetext{
El origen del concepto de crisis es muy remoto. Si nos restringimos a la historia de Occidente, suele ser situado en la Grecia Antigua: lo empleó Tucídides en La guerra del Peloponeso, para señalar el momento de decisión en la batalla pero también la evolución de la peste en Atenas, atravesando ciertos puntos de inflexión, y por supuesto Hipócrates, anclando el tema en la medicina donde estuvo instala-
} 
do con casi exclusividad durante muchos siglos, en los que apareció tímidamente en algunas reflexiones sobre acontecimientos sociales. Habrá que esperar el ingreso pleno a la modernidad (a partir del siglo XVIII y sobre todo del XIX) para encontrar la expresión en su extensión actual... Hoy su ubicuidad, su empleo abrumador, lo ha terminado por convertir en una suerte de comodín difícil de encasillar.

Hence, the tracing of the evolution of the two economic concepts seems to be a far from easy task which, consequently, requires solid research and documentation. However, one may nevertheless ask why exactly the authors have chosen lexicographical works as a starting point for flinging themselves into a task of these dimensions. The highly interesting answer is furnished by the editor in his Introduction (p. 3):

\begin{abstract}
These reference works played an important role in the popularization but also in the systematization of knowledge during the nineteenth century and the early twentieth century, and - judging from the continuing exponential increase in their publication - are still widely used in the support of teaching and, to a lesser extent, research. What is recorded in dictionaries is therefore rather influential, in particular for those works recognized by contemporaries to be authoritative.
\end{abstract}

According to Besomi (p. 16), the "authorship of articles is normally experts and often authoritative" and today these reference works even include "Nobel laureates among their contributors"; he then continues (pp. 16-17):

\begin{abstract}
Nowadays, we expect encyclopaedic articles to depict the state of consolidated knowledge at the time of writing, thus to lie in the rearguard rather than illustrating the latest tendencies of thought. But during most of the nineteenth century and also in the early part of the twentieth, encyclopaedias occasionally housed original pieces of research in many fields, including some articles later developed into textbooks or treatises.
\end{abstract}

The special requirements and features of lexicography, among them that the individual articles are assigned only a certain space within the overall plan of a specific dictionary or encyclopaedia, have a significant impact on the way information and knowledge are transmitted from the author to the reader. The specific articles on crises and cycles analysed in the book cover from only one or two paragraphs in the smallest dictionaries to dozens of pages in the largest ones, i.e. less or even much less than the space necessary to give an all-round and profound treatment of the two concepts as it can be done in, for instance, treatises and textbooks. Ironically, according to Besomi (p. 17), this also has a very positive effect on the articles:

\footnotetext{
The author is thus compelled to be selective, focus only on the essential features, and supply within this space all the necessary information. This produces concise, systematic and synthetic expositions of the subject - whether an original piece of research or a compendium of the facts and shared knowledge about the topic.
}

All this, together with the existence of a large number of economic dictionaries and encyclopaedias of varying sizes, makes "encyclopaedic articles a particularly interesting source of documents for the history of economic thought" (p. 17), thus explaining the particular approach chosen in the book. These reflections, however, can easily be generalised to count for specialised lexicography in general, as it is evident that they do not only have relevance for the study of the history of economic thought but also for the study of the historical evolution of many other branches of knowledge treated in lexicographical works during the centuries, an idea also implied by Mikkelsen (1994) who traces the evolution of Danish specialised dictionaries from the sixteenth century up to our time.

\title{
4. The purpose of economic dictionaries
}

According to the lexicographical function theory developed by researchers at the Aarhus-based Centre for Lexicography, lexicographical works - including specialised dictionaries - may have a great number of different functions in terms of both the types of user to which they are devoted and the types of social situation where the information needs they intend to satisfy may occur, cf. 
Tarp (2008). These functions can be grouped into four main categories: communicative, cognitive, operative and interpretive (cf. Bergenholtz and Bothma 2011), of which at least the first three can be found in economic dictionaries. All the dictionaries and encyclopaedias discussed in the book, although highly varying in their design, size and intended user group, seem to fall within the category of lexicographical works with cognitive functions, although some of them may also have additional functions.

One of these dictionaries which is mentioned but not analysed in detail in the book, is Malachy Postlethwayt's Universal Dictionary of Commerce from 1751-55 (and later published in three other editions). This dictionary may not be particularly interesting for the topic of the book, but it is lexicographically intriguing for several reasons, among them that the author, a British economist of certain reputation in his époque, two years before its first appearance published a dissertation in which he explained his motives for this excursion into the world of lexicography (Postlethwayt 1749). Here, the future "lexicographer" writes that the objective of the planned dictionary is to "more particularly accommodate the Fame to the Trade and Navigation of the British Empire"; this is done in the light of a serious problem, viz that the relevant people frequently do not have a "satisfactory knowledge of Facts in complicated matters of a commercial nature", and that these people, in addition, have neither the time nor the possibility to obtain this knowledge because it is scattered in an infinity of volumes, cf. Postlethwayt (1749: 2):

\footnotetext{
Foreign and domestic trade admitting of so infinite variety of matter, and the knowledge communicated to the world, by those skilled and experienced therein, being scattered in an infinity of volumes, it is no easy matter to have immediate recourse to what may be occasionally requisite... A subject of this extensive nature therefore being reduced to the form of a Dictionary, for alphabetical reference, seems the most naturally adapted to answer these desirable purposes, and especially so, as the compilers can have no motive to deceive.
}

Hence, Postlethwayt had a declared political-ideological objective which, in his understanding, could best be achieved by transmitting the needed knowledge to the relevant people by means of a dictionary. Similar objectives are formulated by other contributors to the dictionaries analysed in the book, for instance by Ambroise Clément in his Introduction to the Dictionnaire de l'économie politique from 1854, resumed by Besomi (p. 210) in the following way:

\begin{abstract}
The targets are made clear in Clément's InTRODUCTION to the Dictionnaire. Ignorance of political economy has had pernicious effects, resulting in the adoption of 'disastrous or absurd measures' (such as protectionism and issuing of the assignats) and encouraging governments to take over responsibilities and privileges which ought to pertain only the citizens, thereby themselves becoming the main cause of instability and insecurity and leading towards universal communism (pp. xi-xii). The educational system after the 1848 revolution attempted to have political economy taught from the viewpoint of the (false) organization of labour, while in 1850 teaching focused on French commercial legislation, that is, it incorporated the protectionist viewpoint. However, the only proper way of teaching political economy was to reflect the understanding of the nature of things observed (p. xiii). The dictionary was seen as 'the best means for the rapid propagation of the main notions' and 'the clearest truths' of political economy (pp. xii-xiii).
\end{abstract}

Only a few decades earlier, another French economist, Charles Ganilh (1826: xxvii), in the Préface to his Dictionnaire analytique d'économie politique, had expressed similar ideas about the relation between dictionaries and science:

Les dictionnaires sont les meilleurs moyens de propager les sciences, d'accélérer leurs progrès, et de les faire arriver rapidement au plus haut degré qu'elles puissent atteindre. Le plus grand perfectionnement de la pensée humaine est dans sa diffusion.

Lexicographical reviews occasionally contain negative comments about works that are clearly influenced by a specific ideology (normally opposed to the reviewer's own ideology), while it is tacitly implied that other works are objective or neutral. However, it should not be ignored that all dictionaries, especially the ones with definitions, to a bigger or smaller extent, are ideologically biased and influenced by the author's or authors' own world outlook. This, of course, is even more 
pronounced within social sciences and disciplines like economics, but it is nevertheless valid for all types of scientific discipline as science always reflects a certain world outlook and, hence, is never completely "neutral". As a rule, it should not be considered a problem that dictionaries are ideologically biased and even conceived with a specific political or ideological objective in mind as long as this objective is communicated and not sold as contraband to the unsuspecting users. This, however, is seldom done by present-day publishers who in most cases prefer to maintain the false appearance of a non-existent objectivity and neutrality, and it is therefore refreshing to meet a number of dictionaries that openly admit their political or ideological affinity.

Whatever their specific overall purpose, all the dictionaries and encyclopaedias consulted pretend to transmit ideas, knowledge and science to their users as a means to achieve their declared or undeclared objective, as it is also summed up by Besomi (p. 12):

\begin{abstract}
Dictionaries and encyclopaedias are planned from the outset with some purposes of rather different nature in mind. All have the explicit purpose of transmitting and making readily accessible knowledge, although there is a difference between informing (making known) and teaching (making comprehensible).
\end{abstract}

\title{
5. Evolution of the user group
}

As indicated above, lexicographical functions are not only defined by the social situation in which relevant needs may occur. Although this situation is the fundamental factor determining the purpose and character of any lexicographical work, the foreseen user group also influences the final design of the work. In this respect it is interesting to see how the elected audience of economic dictionaries and encyclopaedias has evolved and changed during the past centuries, at least in a European perspective, and how this has impacted on the lexicographical works in question.

In the eighteenth century, i.e. in the age of the Enlightenment, two main types of users could be detected, thus leading to two different types of lexicographical works: on the one hand the learned people who needed information in order to keep track of the scientific development reflected in a rapidly growing number of publications, and on the other hand more practical people such as "traders, merchants and occasionally... bankers and industrialists" (p. 14) who needed specialised information directly related to their profession. As a starting point, the needs of the former gave birth to the classical European encyclopaedias whereas the needs of the latter resulted in specialised dictionaries of economics, in the first period frequently called commercial dictionaries, of which some also had an operative function as documented by Tarp (2013).

Starting in the early nineteenth century, the encyclopaedias diversified and gave rise to the socalled conversation lexica and later the popular lexica as a consequence of the still broader public they intended to cover. Concurrently, the specialised dictionaries of economics also went through a transformation in terms of audience. In the first period, before the institutionalization of the discipline, these works could not find "a sufficiently solid market" among the specialists and "were thus also addressed to other categories of readers", for instance, "those in charge of public and collective interests", the "civil servants, merchants and capitalists", etc. (p. 15). But the situation soon changed as Besomi (pp. 15-16) observes:

Towards the end of the century, when the studies of economics were being institutionalized, a new kind of reader appeared on the scene: students... Soon students became a large and appetizable market; this, combined with the exponential growth of the literature, made it interesting to publish readymade reference books for students. Indeed, they have become the main target of economic lexicography, at least in terms of the number of works published. The larger (and more expensive) of these books are meant to be bought by libraries; those meant to be sold to students are much smaller in size, and are therefore much more limited in scope. Similar to the latter are quick reference works addressed to the general public, such as newspaper readers... In terms of effort, the major editorial enterprises are still the scholarly works addressed to academics and graduates students (such as The new Palgrave...) or, if addressed to a generalist public, the large works seeking contributions from wellknown experts in their field (such as the International encyclopaedia of social sciences...). 
Hence, although all the lexicographical works analysed have a declared cognitive function, the fact that they are addressed to various types of users with different characteristics (academics, experts, semi-experts, educators, students, interested laymen, general public, etc.) explains, at least partially, their highly different sizes and other features, a phenomenon that has still not been sufficiently systematised and integrated in the sub-theory of cognitive lexicographical functions. The dictionaries and encyclopaedias presented and analysed by the various authors in the book as well as Besomi's summarising remarks provide a reasonable basis for taking new steps in this direction.

\section{Dictionaries versus encyclopaedias}

Both the title of the book and the material on which it is based refer to dictionaries and encyclopaedias. Although most people have an intuitive idea of what is meant by these two kinds of work, the history of lexicography is nevertheless witness to a protracted discussion on how they should be defined, going back at least to the reflections by d'Alembert (1754) and Diderot (1755) in their respective articles on the subject in their monumental Encyclopaedia which, just like a number of other lexicographical works from the past three centuries, also includes Dictionnaire in its title. This discussion is also taken up by Besomi (p. 4) who uses words like motley and fuzzy to describe the situation:

\footnotetext{
Lexicographical works concerning economics (exclusively or not) are a motley set of objects. As we shall see below..., they include a wide range of sizes, purposes, languages, editorial histories and intended audiences. And they have different names: we have dictionaries, encyclopaedias, encyclopaedic dictionaries, lexica, vocabularies and glossaries, which correspond to different kinds of reference works. The distinction between these kinds of works in practice is rather fuzzy. Several of them - both of general scope and specifically addressed to economics or the social sciences - actually carry more than one of these denominations in their title.
}

Besomi (p. 5) then puts forward the idea that dictionaries and encyclopaedias, although being "complex objects", "can be usefully distinguished on the ground of the nature of their entries". Here, he refers to the lexicographical literature, mainly a certain Anglo-Saxon tradition, according to which dictionaries "define the words of a language", whereas encyclopaedias provide "information on all or some branches of knowledge", although he, in his notes, also mentions the wellknown article in which Haiman (1980) rejected this distinction. The apple of discord is whether or not it is possible to distinguish between semantic and encyclopaedic knowledge. Some scholars like Landau (2001: 6) defends this distinction claiming that "dictionaries are about words, encyclopedias are about things", others like Haiman (1980: 331) oppose the idea with the argument that "dictionaries are encyclopedias", whereas another group of scholars accept the distinction but point to the unavoidable grey area between the two. The discussion, which is imported uncritically into lexicography from linguistics and philosophy, seems endless, mainly because the point of departure is basically irrelevant - for a detailed discussion of this problem, see Tarp (2008: 113-124).

A classification of lexicographical works based upon a phenomenological analysis of the content of the respective articles (entries) does not take into account that these works are above all utility tools which, like all other utility tools, are - or ought to be - conceived with a view to meeting specific types of human needs (in this case various types of punctual information needs that can be satisfied by means of consultation). A much more relevant classification is thus the one based upon the functions of the works in terms of the user needs to be covered, i.e. needs determined both by the type of social situation in which they occur and by the relevant characteristics of the type of user in question. In fact, this was also more or less Diderot's (1755) approach in his article on Encyclopédie where he initially defined the concept based upon its objective:

En effet, le but d'une Encyclopédie est de rassembler les connaissances éparses sur la surface de la terre, d'en exposer le système général aux hommes avec qui nous vivons, et de le transmettre aux 
hommes qui viendront après nous, afin que les travaux des siècles passés n'aient pas été des travaux inutiles pour les siècles qui succéderont, que nos neveux devenant plus instruits deviennent en même temps plus vertueux et plus heureux, et que nous ne mourrions pas sans avoir bien mérité du genre humain.

Today, dictionary, encyclopaedia, and other terms used to denominate lexicographical works have lost much of their original meaning and are, above all, names given by the publishers in order to sell their products; although there is a clear tendency that the biggest lexicographical works, especially with cognitive functions, are called encyclopaedias, and the smallest ones, especially with communicative functions, are called dictionaries, there is also quite a number of other works showing the opposite picture. In fact, this also seems to be the conclusion which Besomi (p. 5) arrives at when he speaks about a continuum with easily discernible extremes:

\begin{abstract}
In practice, the spectrum of the reference works concerning economics and related disciplines listed in the bibliography of specialized dictionaries in Chapter $19 .$. forms a continuum, as scarcely any specialized dictionary can avoid incorporating some encyclopaedic ingredients. Yet its extremes are easily discernible. On one side, we have the writings sharing the features of specialized encyclopaedias, carrying more or less detailed entries not only defining the concept under discussion but also reporting the economic understanding concerning it, supplying essential (occasionally rich) bibliographies and offering a systematization of the subject within the corpus of economic knowledge. On the other side, there are the writings limiting themselves to a definition of the word under examination, or very little more. The latter naturally offer short entries for each heading, so that the former kind of work result in much larger numbers of pages; the length of these volumes (indicated in the bibliography) offers a rough proxy for their position in the spectrum.
\end{abstract}

Of course, Besomi does not take into account all specialised dictionaries when he claims that they cannot avoid "incorporating some encyclopaedic ingredients"; many, maybe even the majority of bilingual or plurilingual specialised dictionaries, also of economics, do not contain definitions, but only equivalents thus providing no encyclopaedic data. Such dictionaries, however, do not have cognitive, but communicative functions, e.g. providing assistance to translation of specialised texts. In this respect, the dictionaries and encyclopaedias analysed in the book are all, irrespective of their specific names, lexicographical works with cognitive functions designed to be consulted at different physical places (home, work place, library, etc.) by different segments of users with different kinds of cognitive (information) needs in relation to different situations (research, study, business activity, general curiosity, etc.). All this - together with the "expected marketability of the product" (p. 13) - explains their different sizes, features, and even names according to national traditions.

\title{
7. Some remarks on the history of economic dictionaries
}

In Chapter 2 with the title $A$ brief history of economic dictionaries, Besomi (p. 27) initially observes:

So far, no complete and detailed history of economic dictionaries has been compiled, in spite of the pervasive usage of such reference tools by laypeople, students and researchers.

The Swiss economist does not pretend to fill the gap in the present book, but he nevertheless considers it possible "to recognize some patterns and attempt a preliminary classification" of this kind of lexicographical work. Although it is impossible to pay justice to this interesting chapter within the framework of this article, it is nonetheless lexicographically relevant to draw the attention to some of his general observations about the chronological, spatial and dimensional distribution of economic dictionaries, as these observations indicate some interesting national and temporal variations which can partially, but not totally be explained by the market as some other factors also seem to be active "behind the scene".

The first observation is that the largest number of economic dictionaries are written in German, followed by English and French. If the relative size of the respective markets is taken into account, this means that "German and, to a larger degree, French readers are supplied with a much 
larger choice of dictionaries than English readers", although this does not say anything about the number printed in each language and, thus, the "density of distribution" (p. 44).

The second observation is that "the vast majority of economic dictionaries are small", i.e. between 300 and 600 pages, and "likely to be of a "popular kind"", a fact suggesting that dictionaries used as a "teaching and learning aid" are more frequent in Germany and France than in Englishspeaking countries, and that this habit "is possibly continued into adult age" (pp. 44-45).

The third observation is about the size of the economic dictionaries published during the past two centuries. Here, statistics show that the publication of medium-sized dictionaries (two or three volumes, or over 1,000 pages) only increased a little since the nineteenth century whereas the number of large works has remained more or less constant since the early twentieth century in spite of "the large increase in their potential users". This means that "the explosion of dictionaries published in the last part of the twentieth century is due almost exclusively to small reference works, which were practically absent in the nineteenth century" (p. 45).

In his fourth observation, Besomi focusses on the distribution of small, medium and largesized dictionaries and documents great variations in some of the main European languages. For instance, the German-speaking countries have produced a third of all small-sized dictionaries while their share of big reference works (four or more volumes) is 46 per cent of the total. In France, most dictionaries published today are small in contrast to the nineteenth century when the country produced "some high-quality works of medium to large size". English works take "a larger than average share of medium-sized dictionaries" while the Italians "lean slightly more than average towards large dictionaries". Based on this uneven distribution of large dictionaries, Besomi (p. 45) concludes:

These monumental works, with long articles discussing the matter in depth, are dedicated more to re-
searchers and teachers than to students; this in turn suggests that German language countries see dic-
tionaries as a way of diffusing knowledge not only among students, but also among educators and sci-
entists, so far as economics and social sciences are concerned, at any rate.

The final observation interferes directly in the ever-going discussion between those scholars who claim that the evolution is always going from a lower to a higher stage and those who defend the view that although this is the general tendency, history in all its aspects only advances in the middle of temporary ups and downs, progress and retrogression, see for instance Dörner (1991). In this respect, Besomi (p. 45) shows that quantity and quality have not evolved along parallel lines:

\footnotetext{
While in purely numerical terms the century of dictionaries is not the nineteenth, as is commonly maintained, but the twentieth, the nineteenth century is surely an epoch when economic and social sciences dictionaries and encyclopaedias were all first-rate, not only in size but also in terms of quality. These features indicate that as the production of economic and social sciences dictionaries is subject to very different national traditions which evolve over time, their usage in learning, teaching and research is also likely to differ substantially. This suggests that perhaps it is not only the specific contents of economic dictionaries that are of interest: the usage that is made of these reference works should perhaps also be subject to investigation.
}

These remarks seem to be highly relevant also outside the realm of economic and social sciences dictionaries, especially in these first decades of the twenty-first century where a new generation of users increasingly opt for other sources than dictionaries when they experience punctual information needs, most commonly some of the many new information tools made available on the Internet and providing quick access to the relevant data, but not always of the needed quality. In this connexion, the uneven distribution of small, medium and large-sized dictionaries among the various language-communities and the factors determining this rather surprising situation also deserve the future attention of the scholars doing research in historical lexicography. 


\section{Conclusions}

Crises and Cycles in Economic Dictionaries and Encyclopaedias constitutes a serious piece of research. The book mainly deals with aspects of the history of economics, but its surprising and unexpected incursion into the world of lexicography leaves some interesting reflections and elements that can be used to further develop the latter. First of all, it provides new knowledge on the history of economic lexicography in particular, and specialised lexicography in general. It does not only document the close relation between the development of science and society on the one hand, and the production and design of dictionaries, encyclopaedias, and other lexicographical works on the other hand. It also shows that this relation is far from mechanical and that it appears dialectically influenced by a whole set of objective and subjective factors which still need to be analysed and understood to their full extent.

Most studies of the history of specialised lexicography have until now focussed on one or a few specific dictionaries, or only on dictionaries belonging to a single country or language community. In this respect, one of the merits of the book is that it studies economic dictionaries published in various European languages and countries during a period of three hundred years and provides interesting information about differences as well as common features and tendencies in the evolution of this branch of lexicography.

Apart from these contributions, Crises and Cycles in Economic Dictionaries and Encyclopaedias also gives rise to some reflections on the academic status of lexicography. The authorship of the lexicographical works analysed in the book without any doubt requires specialised knowledge of economics and many of the authors are in fact authoritative or even vanguard researchers of their époque. The overall purpose of the works is to promote science, specific schools of thought, or "just" knowledge of economics, and the carrier chosen to this promotion is dictionaries and encyclopaedias. The foreseen users or readers of these works are in all cases people, whether experts, semi-experts or laymen, in need of knowledge of economics. In addition, the authors of the book in question are themselves experts in the history of economics who study how their discipline has been treated in a selected set of lexicographical works, just like linguists frequently study how other reference works have dealt with the subject of their discipline, i.e. language.

Within lexicography there is a school or tendency that, in one way or another, considers lexicography to be a sub-discipline of linguistics, and specialised lexicography to be a branch of specialised linguistics or terminology. One of the main postulates of this school is that dictionaries are compiled in order to describe the language and define the words. Although this may be the case for a number of dictionaries, the postulate is in flagrant contradiction to the very nature of lexicographical works as reference tools which the users consult for a lot of reasons, and not only to get a description of the language or definitions of its words. If the same kind of logic was applied to the dictionaries and encyclopaedias studied in the book, then the conclusion would inevitably be that lexicography was a sub-discipline of economics and lexicographical works compiled in order to transmit knowledge of economics, that lexicography was thus "applied economics" just as others consider it to be "applied linguistics". The discussion about the status of lexicography would then be a fight between linguists and economists over the ownership of the discipline, and they would soon get the company of experts from other scientific disciplines. It is not difficult to imagine where such a schizophrenic understanding of lexicography would end.

In fact, the dictionaries and encyclopaedias analysed in the book show in no uncertain manner that lexicography cannot reasonably be considered a branch of linguistics, whether general or specialised. In addition, the existence of thousands of other dictionaries also indicates that neither can lexicography be regarded as a sub-discipline of economics or any other discipline. In this light, the only logical conclusion is the one defended by the supporters of the function theory: that lexicography, on the one hand, is an independent discipline based upon the elements common to all lexicographical works, i.e. the uniting elements that justify the categorisation of these works as lexicographical; and that it, on the other hand, has a great and traditional interdisciplinary vo- 
cation expressed in the fact that lexicographical works, during the millenniums, have covered almost all spheres of science and human activity, cf. Tarp (2010).

Today, lexicography experiences an incipient crisis of a double character: 1) a growing gap between an advanced theory and a conservative practice, and 2) a relative loss of users who increasingly opt to satisfy their punctual information needs by other means. In this regard, Gerolamo Boccardo's brief definition of crisi in his Dizionario della economia politica e del commercio from 1857 is a serious warning of what could happen if no solution is found to this problem:

perturbazione più o meno profonda degl'interessi sociali, perturbazione momentanea e passeggera; altrimenti non sarebbe più una crisi, ma una malattia cronica che condurrebbe a rovina la società.

If the crisis of lexicography continues for a too long period, it could end up as a malattia cronica, a chronic disease that would seriously threaten the discipline's traditional position in society as well as the big perspectives opened by the new computer and information technologies, especially the Internet. In this respect, Crises and Cycles in Economic Dictionaries and Encyclopaedias is stimulating reading and can be recommended to anybody interested in the history of specialised lexicography as well as the development of a general theory of the discipline and the solution of its present crisis.

\section{Literature}

D’Alembert, Jean le Rond 1754: Dictionnaire. In Diderot, Denis/D'Alembert, Jean le Rond (eds.), Encyclopédi, ou Dictionnaire raisonné des sciences, des arts et des metiers. Tome IV. Paris: Briasson, 958-969.

Beinstein, Jorge 2005: El concepto de crisis a comienzos del siglo XXI. Pensar la decadencia. In Revista Herramienta 30, 9-28.

Bergenholtz, Henning/Bothma, Theo J. D. 2011: Needs-adapted Data Presentation in e-Information Tools. In Lexikos 21, 53-77.

Besomi, Daniele (ed.) 2011: Crises and Cycles in Economic Dictionaries and Encyclopaedias. London, New York: Routledge.

Boccardo, Gerolamo 1857: Dizionario della economia politica e del commercio. Torino: Sebastiano Franco e figli e comp.

Chomel, Noel 1709: Dictionnaire oeconomique. Lyon: Pierre Thened.

Clément, Ambroise 1854: Introduction. In Coquelin, Charles/Guillaumin, Gilbert Urbain (eds.), Dictionnaire de l'économie politique. Paris: Librairie de Guillaumin et Cie, ix-xxvii.

Darity, W.A. Jr. (ed.) 2008: International encyclopaedia of social sciences. Detroit: Macmillan Reference USA.

Diderot, Denis 1755: Encyclopédie. In Diderot, Denis/D’Alembert, Jean le Rond (eds.), Encyclopédi, ou Dictionnaire raisonné des sciences, des arts et des metiers. Tome V. Paris: Briasson, 635-648.

Durlauf, S.N./Blume, L.E. (eds.) 2008: The new Palgrave dictionary of economics. Basingstoke, New York: Palgrave Macmillan.

Dörner, Andreas 1991: Von der Gelehrtenrepublik zur Nationalbewegung. Kontexte der Sprachforschung in Deutschland an der Schwelle vom 18. Zum 19. Jahrhundert. In Bergenholtz, Henning/Dörner, Andreas/Karatas, Ramona/Meder, Gregor (eds.), Wegweiser durch die Grammatik von Heinrich Bauer. Verzeichnisse und Erläuterungen. Berlin, New York: Walter de Gruyter, 19-61.

Ganilh, Charles 1826: Dictionnaire analytique d'économie politique. Paris, Brussels: Ladvocat.

Haiman, John 1980: Dictionaries and Encyklopedias. Lingua 50, 329-357.

Landau, Sidney 2001: Dictionaries: The Art and Craft of Lexicography. Cambridge: Cambridge University Press.

Mikkelsen, Hans Kristian 1994: Danske fagordbøger. In Bergenholtz, Henning/Tarp, Sven (eds.), Manual i fagleksikografi. Aarhus: Systime, 258-305.

Postlethwayt, Malachy 1749: A dissertation on the Plan, Use, and Importance, of the Universal Dictionary of Trade and Commerce. London: John and Paul Knapton.

Postlethwayt, Malachy 1751-1755: The Universal Dictionary of Trade and Commerce. London: John and Paul Knapton.

Tarp, Sven 2008: Lexicography in the borderland between knowledge and non-knowledge. Tübingen: Niemeyer. 
Tarp, Sven 2010: Reflections on the Academic Status of Lexicography. In Lexikos 20, 450-465.

Tarp, Sven 2013: Old wisdom: The highly relevant lexicographical knowledge we can get from a specialized dictionary from 1774. In Lexikos 23 (to appear). 